\title{
Passive cooling influencing factors and formation mechanism analysis of the street space in Huizhou traditional dwellings
}

\author{
Bin Zheng*, Jieli Sui \\ Yantai University Architecture School, Yantai 264005, China \\ Corresponding Author Email: archiwolf@163.com
}

https://doi.org/10.18280/ijht.360421

Received: 10 March 2018

Accepted: 1 August 2018

\section{Keywords:}

Huizhou traditional dwelling, street space, passive cooling, influencing factors, formation mechanism

\begin{abstract}
The passive cooling strategy adopted in the street space of Huizhou traditional dwellings boasts great ecological value. This paper probes into the influencing factors of passive cooling and the formation mechanism of these factors. It is concluded that sun-shading should be utilized and wind pressure ventilation should be suppressed in daytime to reduce the heat gain; the space interface should be utilized to boost the accumulation of cold; the thermal pressure ventilation at day should be combined with wind pressure ventilation at night to speed up radiation. Field test and analysis was adopted to probe into the influencing factors of these factors. The mutual influence between these factors helps to maintain a good thermal environment in the street space in summer. And the findings of this study may serve as guidelines for outdoor environment design of traditional residential buildings.
\end{abstract}

\section{INTRODUCTION}

Huizhou traditional dwellings are both a carrier of architectural culture tradition, and an embodiment of profound architectural ecological value. Previous studies have paid more attention to the humanities and history of Huizhou dwellings, but less attention has been paid to the green building technology. Even if there are studies, most of them focus on qualitative research and few quantitative tests. The purpose of this study was to investigate the passive cooling strategy adopted in the street space of Huizhou traditional dwellings. Field test and analysis was adopted to probe into the influencing factors of passive cooling and the formation mechanism of these factors. The findings of this study may serve as guidelines for outdoor environment design of traditional residential buildings. Some technical measures have been applied to the actual project design. Blessed with four distinctive seasons and abundant rainfall, Huizhou has a warm and humid subtropical monsoon climate. The annual average temperature is about $15.8^{\circ} \mathrm{C}$, the lowest extreme temperature is $-12.3^{\circ} \mathrm{C}$ and the highest extreme temperature is $40.0^{\circ} \mathrm{C}$; the perennial wind speed falls between $1.4 \mathrm{~m} / \mathrm{s}$ and $1.6 \mathrm{~m} / \mathrm{s}$; the prevailing wind comes from southwest in summer and northeast in winter; the sunlight condition is good with an annual average sunshine duration of 1,815.7h [1-2]. To adapt to the local climate, the residents in Huizhou adopt a series of passive cooling design strategies, including twisting, deep and narrow streets and lanes.

\section{MORPHOLOGICAL FEATURES OF STREET SPACE}

In material construction, the form of a space depends on the property of the enclosing interfaces. The unique street space in Huizhou traditional dwellings is formed up with such interfaces as blue flagstone pavement, horse-head walls, and flowing water [3]. The streets and lanes are twisting, tranquil, and continuous. The street/lane width is only about 1/5 1/10 of the height of roadside buildings (Figure 1). The street space acts as a centre for material and energy exchange, a regulator of microclimate, space and traffic, and a connector between building cluster and the natural environment [4]. The ecological and aesthetic significance of the street space should never be underestimated.

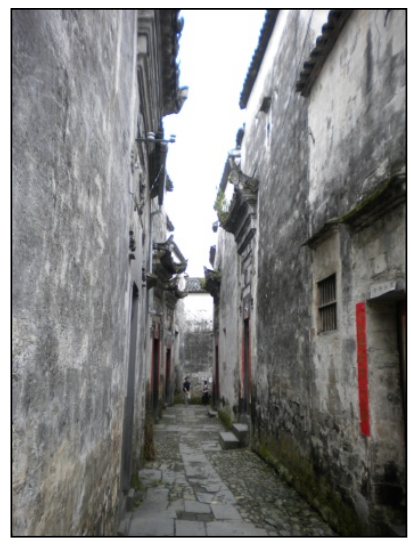

Figure 1. Street space

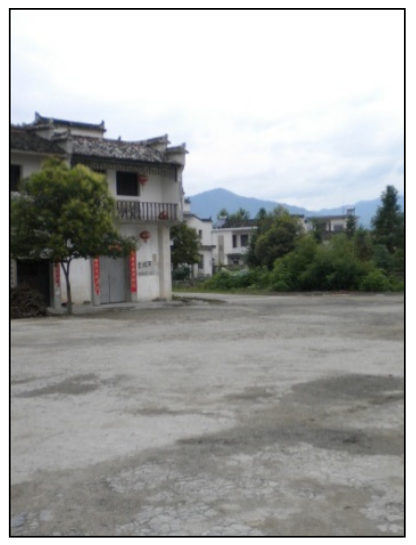

Figure 2. Square space

\section{THERMAL ENVIRONMENT}

The streets and lanes in Huizhou traditional dwellings are known for the pleasant coolness in hot summer, thanks to the proper use of passive cooling strategy [5]. The author compared the actual temperature at two places in Huizhou traditional dwellings, analysed the influencing factors of thermal environment, and examined the formation mechanism of these factors.

Measurement point 1 is located in a $1.5 \mathrm{~m}$-wide lane 
between tall buildings. The height-width ratio is 8 . Measurement point 2 is located in an open square with a few enclosing buildings (Figures 1 and 2). Owing to the different influencing factors of thermal environment, the street space and the square space have different air temperature and humidity on the same day.

From 0:00 to 8:00, the air temperature in the street space was higher than that in the square space. The air temperature difference reached $2.3^{\circ} \mathrm{C}$ at $4: 00$. The difference is attributable to the uneven radiation in the two spaces. Because of the diurnal temperature variation and the obvious ventilation effect at night, the heat accumulated in daytime was radiated quickly in the square space. By contrast, the heat radiation in the street space was slow due to the slow wind speed at night. Coupled with the heat release of heat accumulators, the poor heat radiation contributed to the high temperature in the street space.

From 8:00 to $15: 00$, the temperature in the square space overtook that in the street space. After sunrise, the square temperature surged up under the strong solar radiation, while the street temperature rose slowly due to the sun-shading effect of roadside buildings.

The maximum temperature difference of $4.5^{\circ} \mathrm{C}$ appeared at 12:00, when the street temperature was $30^{\circ} \mathrm{C}$ and the square temperature was $34.5^{\circ} \mathrm{C}$.

From 15:00 to $24: 00$, the temperature in the street space declined slowly from the relatively low temperature, while that in the square space plunged because of the wide space and high wind speed. The temperature trend was basically the same in both spaces [6].

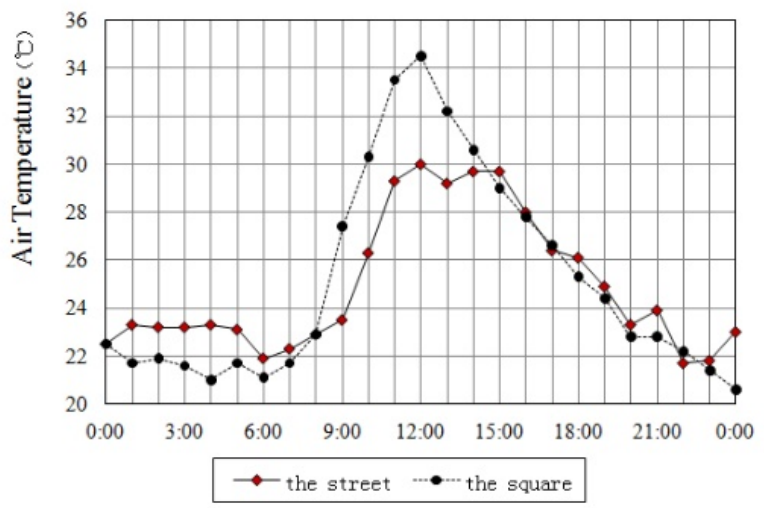

Figure 3. Air temperature comparision chart

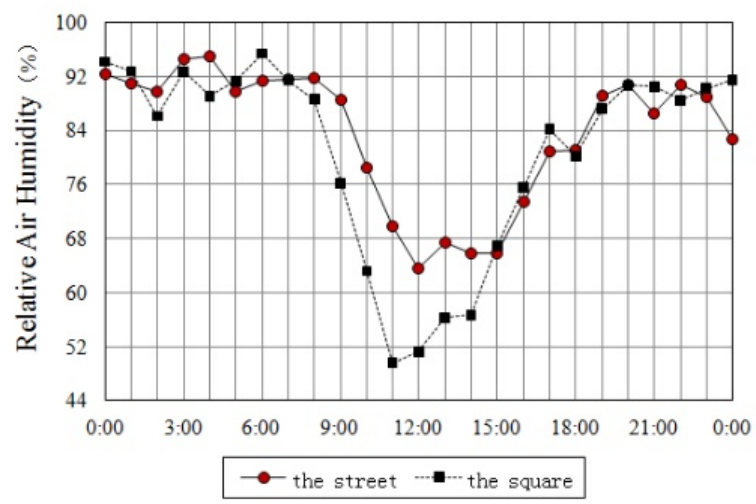

Figure 4. Relative air humidity comparision chart
The trend of air humidity was opposite to that of air temperature. The air was very humid from 0:00 to 8:00 in both spaces, but the humidity difference was prominent; from 8:00 to $15: 00$, the square space is less humid than the street space; the maximum difference occurred at 11:00 (20.2\%). At this time, the air humidity of the square space is $49.4 \%$, and that of the street space is $69.6 \%$; from 15:00 to $24: 00$, the air humidity in both spaces rose continuously with no big difference (Figures 3 and 4).

\section{PASSIVE COOLING INFLUENCING FACTORS AND FORMATION MECHANISM ANALYSIS}

The street space of Huizhou traditional dwellings can maintain a cool microclimate. The cooling effect mainly relies on heat control. In terms of energy transmission, heat control is realized mainly through reducing heat gain, accelerating heat radiation and strengthening heat (cold) accumulation.

If the street space has a lower air temperature than the external space, the heat coming into the street space should be controlled to reduce heat gain; if the street space has a higher air temperature than the external space, the radiation should be accelerated to release heat

In addition, the heat exchange between each interface in street space and the air should not be ignored. The thermal environment in the street space should be kept stable with materials of large specific heat capacity and strong thermal inertia [7].

The above analysis shows that the influencing factors mainly include the following measures: (1) Heat gain reduction by utilizing sun-shading and suppressing wind pressure ventilation; (2) Cold accumulation enhancement by utilizing thermal stability of blue flagstone pavement, water body and walls; (3) Radiation acceleration by utilizing thermal pressure ventilation at day and wind pressure ventilation at night (Figure 5).

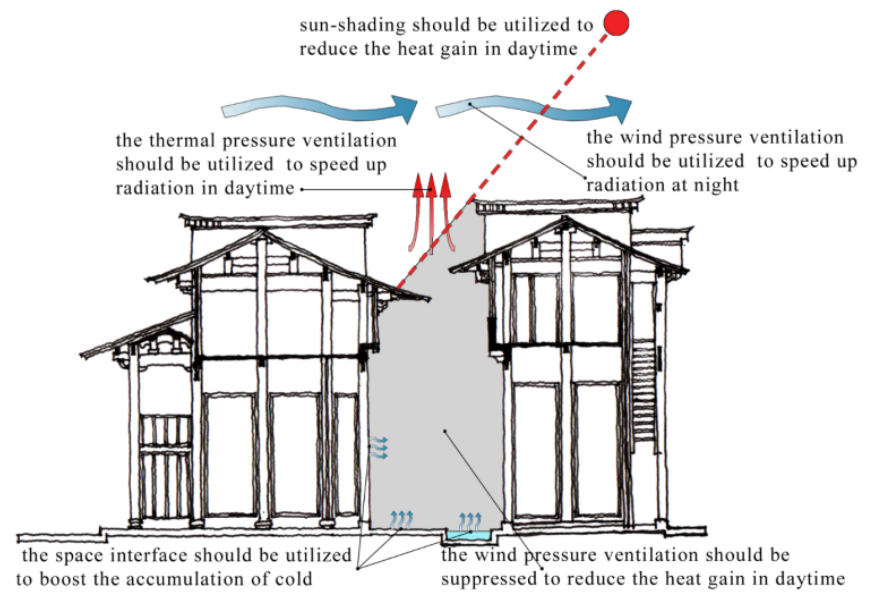

Figure 5. Energy balance in street space

\subsection{Heat gain reduction by utilizing sun-shading and suppressing wind pressure ventilation}

In the street space, the main measure to reduce heat gain lies in utilizing sun-shading of roadside buildings and suppressing natural ventilation at day.

With solar radiation being the main source of air heat in summer, sun-shading of roadside buildings is one of the most 
important measures to reduce the heat gain from the external space [8]. The sun-shading effect hinges on the amount of solar radiation absorbed by the ground. If the street space has a big height-width ratio, most of the ground will stay immune to solar radiation, leading to a limited amount of heat gain. The inverse is also true [9].

The height-width ratio of street space in Huizhou ranges between 5 and 10 . This means the street space is shaded by the roadside buildings in most of the time. In this case, the solar radiation is effectively blocked out, and the heat gain is controlled at a low level (Figure 6).

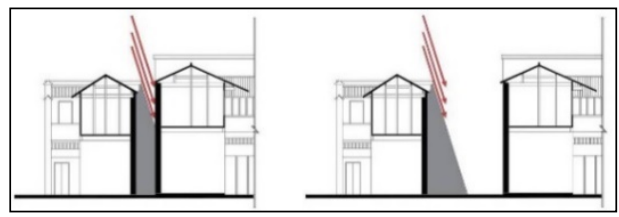

Figure 6. Amount of solar radiation absorbed by the ground at different height-width ratios

The sun-shading effect of walls directly reduces the amount of heat released by heat accumulators. Comparing the ground temperature of street space and square space, it can be seen that the street space had a lower ground temperature than the square space throughout the day.

In the square space, the ground temperature lingered around $25^{\circ} \mathrm{C}$ from 0:00 and 7:00, surged up after 7:00 with the increase of solar radiation, and reached its peak of $50.2^{\circ} \mathrm{C}$ at 13:00; as the solar radiation grew weaker, the ground temperature declined after 13:00, and dropped to a low level after 19:00.

In the street space, the ground temperature was low throughout the day at around $24^{\circ} \mathrm{C}$; the ground receives sunshine for only one hour a day between 12:00 and 13:00; in this period, the temperature rose slightly under solar radiation, and climbed to $29.7^{\circ} \mathrm{C}$ at 13:00. Later, the ground temperature fell back to the low level because of the lack of radiation. Thanks to the sun-shading effect of tall horse-head walls, the ground temperature of the street space is fairly low (Figure 7).

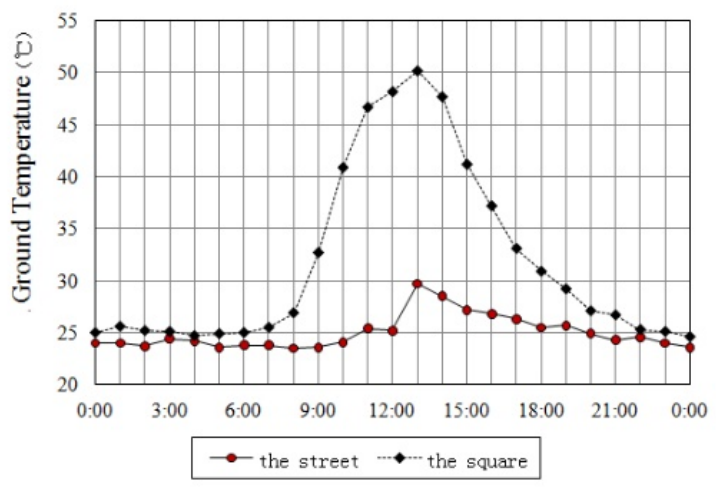

Figure 7. Ground temperature comparison chart

Another way to reduce heat gain is to supress the inflow of external hot air. Most of the external spaces are open squares with rigid blue flagstone pavement. In these squares, the ground temperature and air temperature increase quickly under solar radiation. The highest air temperature is as high as $35^{\circ} \mathrm{C}$ at noon, and the highest ground temperature can exceed $50^{\circ} \mathrm{C}$. The external thermal environment poses a great threat to the microclimate in the street space.

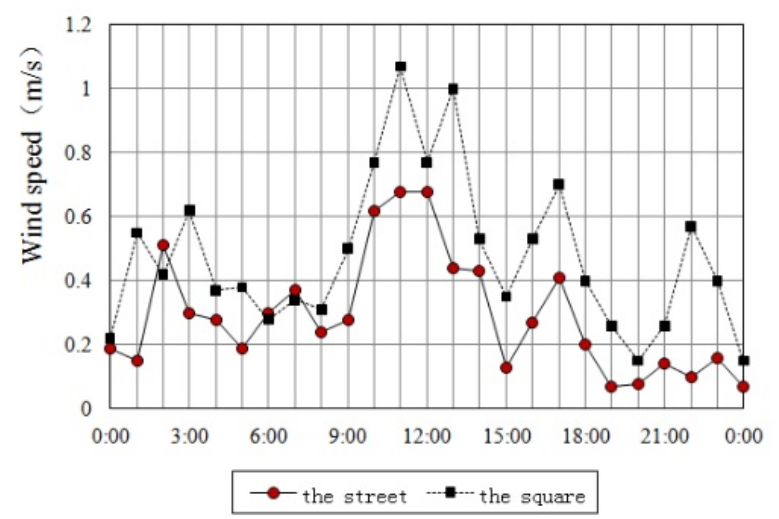

Figure 8. Wind speed comparison chart

The connection between the street space and the external square space is a very small opening, the size of which is limited by the roadside buildings and the width of the street/lane. The structure effectively suppresses the amount of external heat that enters the street space along with the air inflow [10].

Through the wind speed comparison between the street space and the square space, it is clear that the street space has a small wind speed all day long, due to the blocking effect of walls and the depth of streets and lanes.

Specifically, the wind speed was a little faster in the square space than in the street space from 00:00 to 08:00. The average wind speed difference was $0.11 \mathrm{~m} / \mathrm{s}$. In this period, the heat in the square space was basically radiated, and the wind speed was almost as slow as that in the street space.

The wind speed in both spaces underwent an obvious increase after 09:00. The increase in the square space was faster than that in the street space. The wind speed difference kept growing and reached the peak of $0.56 \mathrm{~m} / \mathrm{s}$ at 13:00. At this time the wind speed in the street space is $0.98 \mathrm{~m} / \mathrm{s}$ and the wind speed in the square space is $0.42 \mathrm{~m} / \mathrm{s}$.

To sum up, the daily average wind speed was $0.476 \mathrm{~m} / \mathrm{s}$ in the square, and $0.292 \mathrm{~m} / \mathrm{s}$ in streets and lanes, putting the difference at $0.184 \mathrm{~m} / \mathrm{s}$. The slow wind speed in the street space is attributable to the efficient suppression of the inflow of external heat.

As mentioned above, the temperature in the square space, under the combined effect of different factors, overtook that in the street space from 8:00 to 15:00. The maximum temperature difference of $4.5^{\circ} \mathrm{C}$ appeared at $12: 00$, when the street temperature was $30^{\circ} \mathrm{C}$ and the square temperature was $34.5^{\circ} \mathrm{C}$.

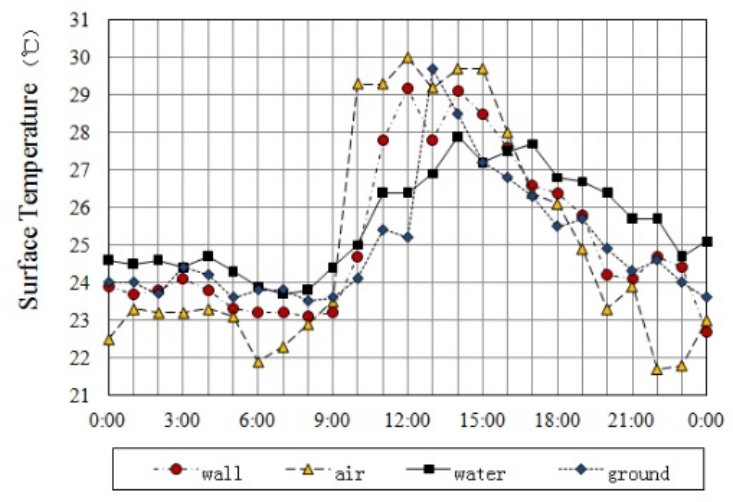

Figure 9. Interface surface temperature comparison chart 
4.2 Cold accumulation enhancement by utilizing thermal stability of blue flagstone pavement, water body and walls

The interfaces of the street space include blue flagstone, water and high walls. The specific heat capacity of water in liquid state is $4200 \mathrm{~J} /\left(\mathrm{kg} \cdot{ }^{\circ} \mathrm{C}\right)$, of the blue flagstone is 750 $\mathrm{J} /\left(\mathrm{kg} \cdot{ }^{\circ} \mathrm{C}\right)$ and of the high walls is $875 \mathrm{~J} /\left(\mathrm{kg} \cdot{ }^{\circ} \mathrm{C}\right)$. These materials boast good cold accumulation capacity and thermal stability is good, and may lead to a certain thermal delay.

In the daytime, the street space temperature varies in a limited range, despite the high air temperature. The stable and low temperature is the result of the good cold accumulation capacity of the interfaces, which absorb heat from hot air and release heat to cold air.

During the test, the surface temperature of cold accumulation materials was maintained between $23.1^{\circ} \mathrm{C}$ and $29.7^{\circ} \mathrm{C}$, indicating that the interfaces have good heat accumulation effect. The temperature increase was curbed by the absorption of the heat from the air [11].

The relatively mild fluctuation of water temperature can be explained by the high specific heat capacity of water and the heat carried away by the water flow [12].

The wall temperature varied a little from 00:00 to 10:00, but rocketed up from 09:00 to 14:00. In the later period, the measured temperature of walls reached $29.4^{\circ}$ at the maximum, which still falls in the range of solar radiation. After 14:00, the wall surface temperature started to decline.

The ground surface temperature was relatively stable from 00:00 to 10:00. However, it surged up to the peak value of $29.7^{\circ} \mathrm{C}$ from $12: 00$ to $13: 00$. Then, the temperature gradually decreased and stayed on a low level. The trend echoes the previous finding that the ground receives sunshine for only one hour a day between 12:00 and 13:00.

With the cold accumulation effect of interfaces, the air temperature of the street space was maintained at a low level.

\subsection{Radiation acceleration by utilizing thermal pressure ventilation at day and wind pressure ventilation at night}

The main method to speed up radiation in the street space is taking away heat by air flow. This strategy is mainly externalized in two forms: thermal pressure ventilation at day and wind pressure ventilation at night.

As mentioned above, when the external air temperature is high at day, the wind pressure ventilation should be suppressed to prevent heat from coming inside. In this scenario, the heat radiation can be accelerated by thermal pressure ventilation.

Most of the roadside buildings have large eaves on the top. Under solar radiation, the temperature on the outer surface of roof tiles is easy to reach $50^{\circ} \mathrm{C} \sim 60^{\circ} \mathrm{C}$. Then, the top air is heated up through long-wave radiation and thermal convection. By contrast, the temperature at the bottom of the street space is very low, owing to the lack of solar radiation and the cold accumulation effect of interfaces. The top-down temperature difference lays the foundation for thermal pressure ventilation. Thus, the warm air moves up because of low density, taking away the heat and speeding up the radiation.

The root cause of thermal pressure ventilation is the thermal pressure difference between the top and the bottom of the street space. The thermal pressure is positively correlated with the thermal pressure ventilation effect. The calculation formula of thermal pressure difference is [13]: where $\triangle P$ : Thermal pressure difference, $\mathrm{Pa}$; $g$ : Gravitational acceleration, $\mathrm{m} / \mathrm{s}^{2}$;

$H$ : Vertical distance between centre line of air inlet and air outlet, m;

$\rho_{\mathrm{e}}$ : Outdoor air density, $\mathrm{kg} / \mathrm{m}^{3}$;

$\rho_{\mathrm{i}}$ : Indoor air density, $\mathrm{kg} / \mathrm{m}^{3}$;

$t_{\mathrm{i}}$ : Indoor air temperature, $\mathrm{K}$;

$t_{\mathrm{e}}$ : Outdoor air temperature, $\mathrm{K}$.

During the test, the top air temperature was $38.3^{\circ} \mathrm{C}$ at noon, while the bottom air temperature was merely $29.2^{\circ} \mathrm{C}$. Since the street space is $9.6 \mathrm{~m}$ tall, the thermal pressure difference at noon is obtained $(3.76 \mathrm{~Pa})$ according to formula (1). The thermal pressure difference resulted in thermal pressure ventilation, and efficiently radiated heat.

There is a large temperature difference at day and night in Huizhou. The air temperature drops quickly in the afternoon and at night, leading to uneven distribution of heat and coldness in partial space. In this case, the wind speed is increased and heat radiation is enhanced at night. Under the wind pressure ventilation, the hot air in the street space exchanges with the cold air in the external space at night, taking away the heat accumulated during the daytime. In this way, the wind pressure ventilation acts as a thermal regulator [14].

The regulation effect is enhanced by the cold accumulation effect of interfaces. The cold accumulators absorb heat at day, lowering the air temperature in the street space. When it comes to the night, the accumulators release heat and work as a cold source in the following day. The higher the wind pressure ventilation at night, the better the cooling effect of the cold accumulators, and the stronger the potential of cold accumulation in daytime.

The street space is too narrow for wind pressure ventilation to enter, and the heat in the space is mainly radiated through wind pressure ventilation at night via the roof of dwellings (Figure 5). During the test, it is measured that the roof top average wind speed was as high as $0.98 \mathrm{~m} / \mathrm{s}$ from 19:00 to 24:00. Under the wind speed, the heat accumulated in the street space could be taken away in time. After 24:00, the wind speed exhibited a descending trend.

\section{CONCLUSION}

Based on the theory of energy balance, Huizhou traditional dwellings have successfully maintained a comfortable thermal environment in the street space. The ventilation in the street space is the combined effect of thermal pressure and wind pressure. The thermal pressure ventilation can take away heat from the street space, while the wind pressure ventilation in the space is smaller than it is in the open space due to the depth of road and blockage of walls. The thermal pressure ventilation at day should be reduced to prevent heat from flowing into the street space, and the wind pressure ventilation on roof should be utilized at night to take away accumulated heat.

Moreover, the sun-shading effect of the street space shortens the time of external building envelope exposed to direct solar radiation, slows down heat gain, and prevents heat from entering into the street space. In addition, the good stability of blue flagstone, walls and water form cold accumulators that also contribute to thermal comfort in the street space. 


\section{ACKNOWLEDGMENTS}

This project was supported by Key Laboratory of Urban and Architectural Heritage Conservation, Ministry of Education, Southeast University

\section{REFERENCES}

[1] Liu J. (2007). Climate and Huizhou dwellings. Hefei: Hefei University of Technology.

[2] Zhang Y, Zhong J. (2011). Analysis of indoor environment of traditional houses in Huizhou. Huazhong Architecture 5: 66-69.

[3] Wang XB. (2013). The analysis on evolution of spatial form of Huizhou traditional dwelling houses. Journal of Anhui Institute of Architecture \& Industry 21(5): 5-9.

[4] Lin BR, Tan G, Wang P, Song L, Zhai GK. (2004). Study on the thermal performance of the Chinese traditional vernacular dwellings in summer. Energy and Buildings 36(1): $\quad 73-79 . \quad$ http://doi.org/10.1016/S03787788(03)00090-2

[5] Li YZ, Li XK, Cao Y. (2015). Comparative study of the street space of the Western of Sichuan and Huizhou folk houses. Huazhong Architecture 6: 176-180.

[6] Ma XL, Xiao YQ. (2005). The condition and analysis of thermal environment in Jinan Quancheng Square. Building Energy \& Environment 24(3): 80-83.

[7] Bourbia F, Boucheriba F. (2010). Impact of street design on urban microclimate for semi arid climate (Constantine). Renewable Energy 35(2): 343-347. http://doi.org/10.1016/j.renene.2009.07.017

[8] Soflaei F, Shokouhian M, Abraveshdar H, Alipour A. (2017). The impact of courtyard design variants on shading performance in hot- arid climates of Iran. Energy and Buildings 143: 71-83. http://doi.org/10.1016/j.enbuild.2017.03.027

[9] Zeng YL, Dong L. (2014). Research on summer microclimate environment of pedestrian street: A case study of the Kuan Zhai Alley. Chinese Landscape Architecture 30(8): 92-96.

[10] Chu CR, Chiu YH, Tsai YT, Wu SL. (2015). Winddriven natural ventilation for buildings with two openings on the same external wall. Energy and Buildings 108: 365-372. http://doi.org/10.1016/j.enbuild.2015.09.041

[11] Wang Y, Shukla A, Liu SL. (2017). A state of art review on methodologies for heat transfer and energy flow characteristics of the active building envelopes. Renewable and Sustainable Energy Reviews 78: 11021116. http://doi.org/10.1016/j.rser.2017.05.015

[12] Jin H, Shao T, Zhang RL. (2017). Effect of water body forms on microclimate of residential district. Energy Procedia 134: 256-265. http://doi.org/10.1016/j.egypro.2017.09.615

[13] Liu XT. (2010). Architectural Physics (Version III), Beijing: China Architecture \& Building Press.

[14] Tse KT, Weerasuriya AU, Zhang XL, Li SW, Kwok KCS. (2017). Effects of twisted wind flows on wind conditions in passages between buildings. Journal of Wind Engineering and Industrial Aerodynamics 167: 87-100. http://doi.org/10.1016/j.jweia.2017.04.011 